\title{
Curriculum reform in South Africa: more time for what?
}

Suellen Shay*, Karin Wolff ${ }^{\alpha 1}$ and Jennifer Clarence-Fincham ${ }^{\beta}$

* University of Cape Town

${ }^{\alpha}$ Cape Peninsula University of Technology

${ }^{\beta}$ Nelson Mandela Metropolitan University

\begin{abstract}
In 2013 the Council on Higher Education (CHE) released a proposal for the reform of South Africa's undergraduate degree arguing that all current 3-year degrees and diplomas, as well as 4-year Bachelor's degrees be extended by one year with an additional 120 credits. This paper argues that the structure proposed provides the conditions for a different kind of curriculum that enables epistemic access and development. The paper firstly offers a set of theoretical tools for conceptualising this enabling curriculum structure. Secondly, drawing on the CHE exemplars, the paper makes explicit the general curriculum reform principles that underpin the enabling structure. Finally, the paper describes how these reform principles translate into qualification-specific curriculum models which enable epistemic access and development. This research is an important contribution to the next phase of curriculum reform in South Africa, what we refer to as a 'new generation' of extended curricula.
\end{abstract}

Keywords: curriculum reform, extended curriculum programmes, epistemic access, knowledge structures, transformation.

\section{Introduction: Background \& Rationale for the Study}

In August 2013 the Council on Higher Education (CHE) released 'A proposal for undergraduate curriculum reform in South Africa: A case for a flexible curriculum structure' (CHE, 2013). The proposed policy argues that the current curriculum structure poses a systemic obstacle to access and success that can only be overcome through deliberate intervention at a systemic level. The CHE proposed that all current 3-year degrees and diplomas, as well as 4-year Bachelor's degrees be extended by one year with an additional 120 credits. The case for structural curriculum reform is extensively argued (and not repeated here). The proposal clearly acknowledges that an extended structure is a necessary though not sufficient condition for curriculum reform. It is necessary because as Ndebele argues in the preface "the conditions on the ground dictate a fundamental systemic review of the undergraduate curriculum. More programme time ... more system self-awareness" (CHE,

\footnotetext{
${ }^{1}$ Corresponding author email: wolff.ke@gmail.com
} 
2013: 9). Thus a structural change is only a 'game changer' if it enables a different kind of curriculum.

For nearly 30 years South African higher education institutions have been offering through their academic development programmes various versions of extended curricula. The proposal draws on the experience of these programmes - both their strengths and limitations - to argue for a number of 'essential features' or principles of curriculum reform: foundational provision, developmental support through key transitions of the degree, curriculum enhancement through 'breadth' and curriculum enrichment through key literacies.

These principles point to what is fundamentally different about the proposed curriculum structure: it provides the conditions for a different kind of curriculum model that enables epistemic access and development. The concept of 'epistemic access' is discussed further below.

In order to illustrate what these high level principles might look like across different knowledge domains and qualification types, the proposal includes curriculum exemplars for four Bachelor's degrees: BSc Engineering, BCom, BSc and the BA/BSocSci, and one Diploma (Dip Engineering). These exemplars - produced by academics from across South African higher education institutions - translate the curriculum reform principles into curriculum models for each of the qualifications.

The heated debate around the CHE restructuring proposal led to the launch of a collaborative research project, funded by the Department of Higher Education and Training (DHET) collaborative Teaching Development Grant. The project sought to clarify the key principles informing the proposed curriculum reform. More specifically, if the proposal was fundamentally about more time, the question is, more time for what? How are the curriculum models being proposed different to the existing structure? Given that existing extended curriculum programmes (ECPs) also feature 'more time', how are the proposed models' use of additional time different?

The collaborative project has two phases and the paper presents the key findings from phase one of the research project. In phase one we surface the key principles that underpin the curriculum reform models both at a high level and at the level of the specific qualifications. This was done through an analysis of the exemplars, followed up with interviews with exemplar leaders for each of the five qualification types. The analysis of the documents and the interviews were structured around four analytical categories: selection (what?), pacing (how much?), sequence (what order?), and evaluation (what counts?). The paper unfolds in two parts: firstly, we offer some tools for conceptualising curriculum structure that emerge from the analysis of the exemplars and the interviews with staff. Secondly, we use the conceptual tools to describe the various curriculum models that emerge across the five exemplars. In phase two of the research project (not reported on here) we pursue to a further level of specificity how the implementation of these principles might vary across degree types and in different institutional contexts.

As noted above the CHE proposal argues that structural change is a necessary but not sufficient condition for achieving the goals of equity of access and equity of outcomes. This paper acknowledges that enabling epistemic access and progression is not simply a matter of curriculum structure or more specifically only about more time. There are many other necessary conditions for comprehensive reform which include mechanisms for placement 
onto different curriculum pathways, alternative forms of pedagogy and assessment, as well as resources required for implementation, for example, educational development expertise, academic staff development, and a range of infrastructural needs. It is profoundly about particular ways of teaching that promote particular ways of learning (Case, 2011). However, the proposal notes that "the exemplars offer a valuable basis for further curriculum analysis and development in institutions... and that an elaboration of these will be a key contribution to implementing the new structure" (CHE, 2013: 122). This research is an important contribution to the next phase of development of, what we refer to as, a 'new generation' of extended curricula. We echo the warning of Badat (2015) who, with specific reference to the CHE proposal, argues that

unless much needed academic transformations are instituted, we will deny opportunities to people from socially subaltern groups, tragically waste the talents and potential of these individuals, and perpetuate injustice. This compromises democracy, which proclaims the promise of greater equality and a better life for all people.

The demands for transformation initiated by the \#RhodesMustFall and \#FeesMustFall student protests during 2015 point to the very urgent need for research-informed systemic and structural reform. This paper contributes to the debates about the nature of this reform.

\section{Conceptualising Curriculum Structure}

Curriculum can be differentiated into the intended and the enacted. The former refers to the curriculum structure and design, the latter to how that design is implemented and its effects on learning and learners. The focus of much academic development scholarship has been largely on the latter, on the learning and teaching that is enacted through a particular curriculum experience. There has been less attention given to the curriculum conditions that constitute the learning. Focusing attention on these conditions requires a conceptual language for discussing the intended curriculum.

This paper offers a set of theoretical tools for conceptualising curriculum structure, in particular the curriculum conditions that enable epistemic access. This conceptualisation is informed by the social realist school of sociology of education, in particular the work of Basil Bernstein. Bernstein defines curriculum as "what counts as valid knowledge" (1975: 85). Whatever else it may do, curricula must enable access to this knowledge - it must enable 'epistemic access'. 'Epistemological access' - a term first coined in the 1990s - is used by Morrow (2009) to highlight the potential disjuncture in the early post-apartheid days between formal access to the institutions that produce knowledge and access to this knowledge; as Muller (2014: 255) captures it, "meaningful access" is access to the knowledge 'goods'. Morrow argued that if one of the key purposes of higher education is to produce knowledgeable citizens then it follows that one of its core functions has to be to give students access to knowledge, access to 'epistemic values' - the forms of inquiry of the disciplines. This is more than disciplinary content; it is the "grammar of inquiry" (2009: 37). Morrow elaborates on this: 
In this way of talking, any established and disciplined practice, such as civil engineering, teaching, mathematics, legal practice, biochemistry, history or primary healthcare, can be said to be constituted by a particular (but not necessarily exclusive) grammar...Higher knowledge of the practice in question would consist in understanding the constitutive grammar of the practice, the grammar that makes the practice what it is (Morrow, 2009: 120).

The notion of the 'grammar of the practice' is somewhat cryptic. What is 'epistemic access' access to? In order to answer this question, we need ways of conceptualising different types of knowledge, disciplinary knowledge structures, curriculum 'logics' and qualification purposes. Then we turn to a discussion of the implications of these differences for different curriculum models.

Firstly, different types of knowledge: Muller (2015), drawing on Winch (2013), argues that epistemic access is access to both the propositional knowledge (know-that) and procedural knowledge (know-how) of the discipline. According to Winch propositional knowledge is not isolated propositions, but propositions that are embedded within a conceptual structure (2013: 130). Procedural knowledge is the 'how to do something' but Winch argues that what is critical is the way in which the propositional and the procedural knowledges are related to each other: some mastery of know-that is required for know-how. The complexity of this relationship is underestimated in discussions about 'skills'. Relevant to curriculum design is how both the know-how and know-that ascend epistemically; in other words, how they increase in conceptual complexity (Winch, 2013). Hence, why sequence in curriculum is critical.

The challenge for curricula is how to make visible the epistemic obstacle course, how to illuminate the "differential internal epistemic and pedagogical architecture that students have to negotiate" (Muller, 2015: 415). While these challenges may be more acute for students from less privileged educational backgrounds, they are not their preserve alone. Muller argues that at least with reference to the areas of Science, Technology, Engineering and Mathematics (STEM), the rapid growth in the specialisation of knowledge will require greater explicitness in the future curriculum for all. "Demands for access to, and demands for, STEM knowledges and practical know-how will also escalate, bringing larger and more diverse constituencies into the universities" (Muller, 2015: 415).

To further elaborate on the notion of epistemic access, we note that the particular combinations and progressions of know-that and know-how will vary depending on the structure of the knowledge that constitutes the discipline/s of the degree. Bernstein (2000) uses the notion of 'structure' to refer to the manner in which the knowledge grows or is produced. Differences between them are characterised by Bernstein using the metaphors of 'hierarchical' and 'horizontal': natural science disciplines are broadly characterised as hierarchical, in other words, they grow cumulatively, by subsumption of phenomenon into increasingly more higher-order explanatory principles/laws. The humanities are characterised as 'horizontal'. They grow by the development of new 'languages' or theories that do not necessarily replace one another but are on offer as competing explanatory frameworks. These metaphors are limited but they alert curriculum designers to the very different epistemic 
conditions of these disciplinary domains. The epistemic 'journey' into science will not be the same as that into humanities due to the different structures of their respective disciplines.

Finally, the particular combinations and progressions of know-that and know-how will vary depending on the purpose of the qualification. The Higher Education Qualification Sub-Framework (HEQSF) specifies three broad qualification pathways - vocational, professional, and general formative. These pathways point to different curriculum purposes and hence different 'logics', that is, what gives the curriculum sense or meaning (Muller, 2009). Formative degrees are typically constituted by a collection of 'singulars' or disciplines that have strong autonomy (Bernstein, 1975). For example, a science degree is made up of chemistry, physics, and mathematics. The coherence or logic of this kind of curriculum is conceptual (Muller, 2009), that is to say that the curriculum 'spine' is made up of the basic conceptual building blocks of those disciplines packaged up into, for example, Chemistry 100, 200 and 300. Similarly, a humanities degree is a collection of 'singulars' such as history, sociology and politics, each of these with their own distinct know-that and know-how knowledge. Unlike science the conceptual progression of a humanities curriculum may be more arbitrary, evidenced by the heated debates over what goes in Sociology 100, 200 and 300. Nonetheless the coherence is still conceptually-driven.

In contrast to this collection of 'singulars', professional degrees are more 'integrated'. While in the foundation years they may start as a collection of singulars with a conceptual logic - for example the early years of a medical degree consisting of physics, chemistry, anatomy - at the advanced levels, the 'logic' shifts towards a more contextual logic given the outward professional orientation of the degree. The curriculum at the more advanced levels assumes basic foundations are in place and requires integration across the 'singulars' through application of foundational knowledge to the 'problems' of the profession.

These are fundamentally different epistemic journeys. The formative journey is one of increasing complexity along a conceptual spine. The professional journey requires fundamental epistemic transitions, for example, in engineering from one kind of know-that and know-how of the basic sciences to another of the applied sciences to yet another of the design disciplines. Thus the epistemic transitions of the collection code curricula are different to those of the integrated code. There are also important differences in terms of the acquisition of professional identities in the latter. This is not elaborated in this paper but the ways in which knowledge specialises the knower is a crucial feature of epistemic development in vocational and professional qualifications.

The implication of the above is that while there may be a set of general principles that underpin the proposed structural reform (and these are discussed below), beyond these general principles, curricula which enable epistemic access will have different requirements depending on the knowledge/disciplinary domain (science vs. humanities) and the qualification type (formative vs. professional vs. vocational). The analysis that follows firstly extracts these general structural principles and then explores their application across a range of qualification types. 


\section{More Time for What: Principles of an Enabling Structure}

We now turn to make explicit the general principles of the enabling structure. In answering the question 'more time for what?' the CHE task team proposal argues that there are three structural problems that curriculum reform needs to address.

The first is "discontinuity between secondary and higher education in South Africa" (CHE, 2013: 17), which is referred to as the 'articulation gap'. This is a structural gap which arguably could be addressed by improvements in the schooling sector but until such time as this happens higher education must interrogate and adjust where necessary its entry level assumptions. Drawing on decades of experience in 'bridging' this gap through extended curricula for talented but educationally disadvantaged students, the report stipulates that the extra time must be used to "provide additional curriculum time for foundational learning" (CHE, 2013: 18). This involves “...not only subject knowledge but also academic skills, approaches to study, background or contextual knowledge and forms of social capital" (CHE, 2013: 17). Thus in response to the systemic structural gap between secondary and higher education, a key feature of the restructured curriculum is the normalisation of foundational provision. In other words, it is not an add-on for a minority group of students ${ }^{2}$ but it is integrated into and part of regular degree provision.

The second 'structural' problem that the curriculum reform must address is 'key transitions' through the undergraduate curriculum (CHE, 2013: 19). As noted above, these are essentially 'epistemic' transitions. Thus a further key feature of the restructured curriculum is reform beyond foundational provision into second and third year. The third structural problem calling for "urgent attention [is curricula to be] enhanced to meet contemporary local and global conditions" (CHE, 2013: 19). This is the formation of a particular kind of graduate through "broadening the curriculum to include learning that is professionally and socially important in the contemporary world ... and that lays the foundations for critical citizenship" (CHE, 2013: 19).

To summarise the general principles which characterise the proposed reform, at the entry level there is a recognition that serious knowledge gaps need to be filled given problematic curricular assumptions about students' prior knowledge. There is further acknowledgment that addressing these gaps alone will not suffice and that beyond entry level there is a need to scaffold students' epistemic development. Finally, there is a need for a structure which enables greater 'breadth' of exposure in order to produce graduates for the contemporary world. Beyond the general principles for an enabling curriculum structure, what the data show is that how epistemic access is enabled varies across two dimensions: the structure of the disciplinary knowledge and the purpose of the qualification. What follows is a description of how these reform principles translate into qualification specific curriculum models that enable epistemic access and development.

\section{Bachelor of Science Curriculum Model}

How does the proposed curriculum model for the Bachelor of Science enable epistemic access and development? Or, more time for what?

\footnotetext{
${ }^{2}$ Nationally only $15 \%$ of the students are enrolled on extended degrees (CHE, 2013: 73).
} 
The BSc model proposes a "redistribution of the load over four years" (CHE, 2013: 236). The aim is to "facilitat(e) the successful assimilation of scientific concepts and ...translat(e) these into operational skills" (CHE, 2013: 230). This succinctly encapsulates the notion of epistemic access being about the know-that (the concepts) and the know-how (the procedural skills). The question is, what kind of BSc structure would enable this?

One way of conceptualising the notion of redistribution is that the BSc model is a 'stretch' of the existing 3-year curriculum. This is both a helpful and limited metaphor. It is helpful in that it signals that the selection and sequence of the conceptual building blocks for any science curriculum, whether 3 or 4-year, are largely the same. The 'singulars' that make up the BSc are hierarchical knowledge structures with strongly sequenced conceptual building blocks. The BSc curriculum coheres around a largely uncontested conceptual spine. There will be broad agreement among experts about the content and sequence of Chemistry 1-2-3, Physics 1-2-3 etc. One way to conceptualise the difference between the BSc model and the existing 3-year curriculum is that the conceptual 'spine' is simply stretched. Or drawing on another metaphor, the epistemic terrain to be covered remains unchanged, there is simply more time to explore and cover the ground.

The question is, where is the stretch? The stretch could be predominantly (or only) in the first year, stretching 'back' to the school syllabus covering missing (or badly covered) content. The exemplar is clear however that the BSc model is not only this. It distinguishes itself from what it calls 'front-ended' models of foundation provision or a $1+3$ model. What distinguishes it is that the 'stretch' is in two places. It does indeed 'stretch back': semesters 1 and 2 of the existing 3-year BSc (or the first 120 credits) are stretched over semesters 1, 2 and 3 of the proposed model into 180 credits. The additional 60 credits in the first semester provide 'introductory/foundational material'. This is an intentional strategy to address the articulation gap between the levels of preparedness in the basic sciences of maths, chemistry and physics. The second 'stretch' is that semesters 3 and 4 of the 3 -year BSc - (120 credits) are stretched over semesters 4, 5 and 6 into 180 credits. The final year of the BSc model is (in theory) identical to the final year of the 3 -year degree, in other words, the existing semester 5 and 6 are the same as semester 7 and 8 of the model. This second 'stretch' points to a fundamental difference between the models of existing extended degree programmes and the proposed curriculum reform model of the CHE exemplar: the former largely 'stretches' back and leaves the rest of the curriculum intact. The proposed BSc curriculum model acknowledges the need for 'more time' across the degree.

The limitation of the notion of 'redistribution' or 'stretch' is that it might suggest that the model proposes no new content. This is not the case. Recall that the purpose of 'stretching' is not simply more time but making the "epistemic architecture" (Muller, 2015: 415) of the various disciplines more explicit. As when stretching fabric where the actual strands, weave and texture become more visible, the extra time is there to make more explicit and more visible the know-that and know-how of the specific disciplines. How this is done is a matter of pedagogy - the selection of material, the assessments that are set, the kinds of learning that are promoted. The assumption of the proposed model is that this 'explicitmaking' pedagogy needs more time. 
So in summary, in the BSc model more time (60 credits) is used in year 1 to consolidate essential basic conceptual building blocks, and additional time (60 credits) is allocated to year 2 and 3 to build on those epistemic foundations.

\section{Bachelor of Humanities Curriculum Model $^{3}$}

The Bachelor of Humanities (BHum) is also a formative degree. Like the Bachelor of Science, its coherence is conceptual but there are important differences given that the 'singulars' that make up the BHum are typically more 'horizontal' in their knowledge structure; they develop through the acquisition of different perspectives/theories. This results in a different kind of epistemic journey and thus a different model of curriculum is required.

The exemplar summarises the difference between the existing 3-year degree and the BHum model as the latter would include the same amount of 'content' but the added credits "would allow for greater focus on a vertical 'spine' of concepts and practices running through the four years" (CHE, 2013: 247). We return to the distinction between content and concepts below. The BHum model stresses, as the BSc does, that epistemic access is both about knowthat (the concepts/content) and the know-how (practices).

In answering the question - more time for what? - there is a strong emphasis on the know- how but know-how that cannot be separated from the know-that. Thus the vertical 'spine' or 'thread' of the curriculum is in fact a 'braid' of know-that and know-how. The know-how is referred to as 'discipline-related academic practices': these are the thinking/reading/writing practices of the disciplines (also referred to as 'academic literacies'). Their inseparability from the disciplines is stressed repeatedly: "At the root of academic reading and writing, therefore, are a set of discipline-based principles and values related to what counts as knowledge and how knowledge can be known" (CHE, 2013: 245).

We turn to two different kinds of know-that in the exemplar: the distinction between 'content' and 'concept'. Inferred in the exemplar is the practice of designing Humanities curricula with reference to a particular 'content' logic. The example given is a Sociology curriculum which focuses on sociology of the family in the first year and 'progresses' to the sociology of education in the second year and perhaps to sociology of the South African economy in third year. It could be argued that this content selection and sequence is rather arbitrary; it may have more to do with the interests and specialisations of the academic staff than any inherent progression in conceptual complexity. In this way of constructing a curriculum the requisite academic practices (or know-how's) are assumed to be present at entry or acquired along the way. In this way of thinking, the skill of, for example, critically reading a text is acquired by being required to critically read a text.

In contrast the BHum model is designed using the following principles: keep the 'content' coverage the same but use this content to develop the vertical spine of concepts and practices identified as central to the disciplines. The added year allows for more time to develop the 'spine' of concepts and practices. Interestingly, in contrast to the 'content' (family vs. economy) the conceptual logic is less arbitrary. It is argued that there is a

\footnotetext{
${ }^{3}$ The exemplar is called Humanities and Social Science Bachelor's Degree. We refer to it as Bachelor of Humanities (BHum) for short.
} 
'hierarchy of concepts and practices' that is necessary to build up a particular kind of knower/gaze, for example, a historical or sociological way of viewing a particular problem. The example is given from History where the ability 'to assess secondary sources' precedes the ability to 'use primary sources based on archival research'. So, more time for what? The answer is, additional curriculum space is given to the essential conceptual know-that and especially the know-how of the disciplines which were previously assumed to be acquired.

So what is the best curriculum model for this? Here different options present themselves ${ }^{4}$. There is agreement that the best model will keep the know-that of the concepts close to the know-how of the practices. Thus the allocation of extra credits to 'generic' reading and writing skills is firmly denounced by the exemplar. From this point there are two options: One model simply extends, for example, SOC 100, 200, 300 into SOC100, 200, 300 and 400, and embeds the conceptual and practice-based know-how into these core modules of the major. Another model is to 'front-load' the curriculum with developmental modules that provide 'dedicated' curriculum space for these concepts and practices. Even in this model its success depends on the conceptual/practice threads introduced in the foundation developmental modules being pulled through upstream. One way of doing this is to give second and third year level courses additional space/credit values - they are 'augmented' through extra lectures or tutorials. Both models agree on the epistemic inseparability of the know-that and the know-how - whether these are fully embedded or partially embedded in core modules depends on issues of autonomy, resources, and staff expertise.

\section{Bachelor of Science (Engineering) Curriculum Model}

Given that the epistemic taproot for an Engineering degree is Science, it is not surprising to find similarities between their epistemic journeys. There are however two important interrelated differences which affect the curriculum model. Firstly, in Engineering the epistemic journey experiences a number of key transitions and secondly, the professional purpose of the degree means that the curriculum logic is both conceptual and contextual. With respect to the epistemic transitions, in science epistemic progression is largely a matter of increasing conceptual complexity (though clearly there are differences across the various science disciplines). By contrast in Engineering there are marked differences in the know-that and know-how as the curriculum progresses. The exemplar is clear that extra time is needed to support "transition points at which students are expected to be able to think in different ways and deal with different types of knowledge" (CHE, 2013: 170). These are characterised as transitions from school to university, basic sciences to engineering sciences, engineering sciences to design, from knowledge of discrete subjects to analysis of systems and integration of knowledge.

In addition to adherence to key conceptual building blocks, the logic of the curriculum must simultaneously adhere to the requirements of practice or demonstrate contextual coherence. The exemplar notes that the curriculum needs to produce "qualified engineers who have the knowledge, skills and attributes to contribute to the quality of life of the societies in which they work and who are able to be gainfully employed" (CHE, 2013: 170).

${ }^{4}$ Only one of these models is presented in the report exemplar, the other model emerged in the interview. 
This signals that epistemic access is an induction into know-that (knowledge) and know-how (skills, as well as attributes) marshalled for particular professional purposes.

What are the implications of this for the model of curriculum? The key difference between the existing and the proposed model is the inclusion of what are called 'developmental courses'. In the exemplar there are 10 additional courses that account for the additional 120 credits. These courses are spread thickly at entry and more sparsely toward the exit of the qualification - a kind of a triangle of development support. Of the ten courses four are in the first year, like the BSc model, in recognition of the need for extra foundational credits that 'stretch back' and fill gaps, to firm up shaky or non-existent conceptual foundations. These are foundations in mathematics, physics and chemistry. There is an additional Introduction to Graphical Communication for students who have no background in technical drawing. In second year, there are three courses supporting the epistemic transition from basic to engineering sciences and the particular epistemic requirements of design. In the third year, there are two courses to support students' transitions into modelling and systems. Each of these transitions represent not simply new content, or new concepts, but they are as one interviewee reported 'fundamentally different ways of thinking'. These are different "grammars of inquiry" (Morrow, 2009: 37)'. The last additional course - in the fourth year provides advanced communication. The contextual coherence becomes more pronounced further along the degree. These are the professional requirements - such as professional and technical communication, professional and ethical behaviour and the importance of sustainable development.

At the risk of over-simplification, the curriculum model in Science could be characterised as a 'stretch', in Hum it is a 'wrap', in Engineering it is essentially a 'thickening' of support which enables a smoother passage across a changing epistemic topography. The metaphors are not perfect but the point is that each extended curriculum structure/model is responding to the particular epistemic demands of the degree.

\section{Bachelor of Commerce Curriculum Model}

How does the proposed BCom model enable epistemic access and development? In terms of the epistemic terrain to be covered, there are similarities between the BSc (Eng) and the BCom. They have common epistemic taproots in the sciences and mathematics in particular, and both have a professional orientation. The general BCom is a formative degree, but has a strong professional orientation. The exemplar states that the purpose of the re- structuring is to enable graduates to "attain the knowledge levels and attributes required by employers and relevant professional bodies" (CHE, 2013: 202).

The intention of the BCom model is two-fold. Given the under-preparedness of incoming students, particularly in mathematics but also in areas such as accounting and economics, some of the extra time is intended to strengthen conceptual foundations. The second aim is to broaden students' knowledge of the field. This broadening is seen as important given the reality that many students come into a BCom with naïve motivations - as one interviewee noted, "students decide to do a BCom with the idea of, "I want to make money, I want to have my own business"'. Thus what can be inferred from the exemplar is 
that epistemic access and development is know-that and know-how but with a strong orientation towards particular professional context within the field of commerce and business.

This strengthening of foundations and broadening of experience happens as with the BSc (Eng) model through ten courses that make up the extra 120 credits. Eight of these courses (foundation/enrichment courses) are in the first year and two (developmental courses) in second and fourth. Thus, consistent with all the models above, the 'extra time/credit' is 'thick' in first year but spreads beyond first year. In terms of the foundation courses, the assumption is that many students have weak mathematical grounding, limited information technology skills, and often have very limited exposure to the world of business. Thus six of the ten courses are Mathematics, Computer Application, Statistics, and three introductory courses in Economics and Accounting. Economics and Accounting are standard BCom courses but the foundation courses offer a "structured introduction to skills, history, context but also cover the $1^{\text {st }}$ year material" (CHE, 2013: 218).

In addition to these first year courses intended to broaden students' knowledge and experience, there are two semesters of introduction to Integrated Business Studies. These courses are "language-rich and will enable the development of business acumen, familiarity with the discourse and practical applications in realistic contexts" (CHE, 2013: 217). Following from Business Studies in years 2 and 3 there are courses in Business Ethics, Business Law, Commercial Law and a final capstone course in year 4. These courses constitute an important strand in the curriculum of exposure to the broader field or curriculum 'breadth'. It is not clear whether this strand is more know-that or 'know-how. Neither is its relationship to the other strands clear, for example, the majors in economics or accounting.

Like the BSc (Eng) model, there is an acknowledgment of 'critical articulation and transition points' but these are not described as epistemic transitions. They appear to be more about transitions of 'context' - from school to University with its shift in volume and complexity of work, from university to the world of work and the need for graduate attributes. The third transition is what they call the 'gate-keeper' courses, for example, the transition from Accounting 2 to 3 with its minimum requirements. The transition between different kinds of disciplines is not noted, for example, Economics and Management Studies have different knowledge structures with the former having some features of hierarchical knowledge structures and the latter more horizontal.

\section{Diploma of Engineering Curriculum Model}

There are similarities between the BSc (Eng) and the Dip Eng model in terms of the epistemic journey. Both curricula are premised on a progression from foundational basic sciences to integration across these knowledge domains for application and problem-solving. One of the differences, however, is that the Diploma has a stronger contextual coherence given its strong orientation towards practice: "the principle of progression is across the different knowledge areas towards increasingly complex integrated forms of practice" (CHE, 2013: 184). Once again we see a strong relationship between know-that and know-how where in this case the 'know that' enables, indeed needs to serve the 'know how'.

In order to understand how more time enables epistemic access and development towards these 'integrated forms of practice', it is useful to contrast it with the existing 
extended curriculum. The extended curriculum is the provision of extra time to complete the first two or three semesters of mainstream content, but with additional foundational support in core content, notably in subjects such as physics, chemistry and mathematics. This approach, together with a range of 'academic support' initiatives (academic literacies and mentorship programmes, for example) is generally targeted at bridging the structural gap from secondary to tertiary education. From the end of first year or mid-way through second year, the extended curriculum reverts to mainstream. This is essentially a $1+3$ model.

In contrast to this existing extended curriculum form of support, the models for the engineering diplomas stress that the purpose of the qualifications is the provision of "a sound knowledge base in the discipline... and the ability to apply their knowledge and skills to particular career or professional contexts" (CHE, 2013: 187). In terms of selection, the core disciplinary knowledge areas see allocation of more time for deepening and extending the same traditional 'content', not only as a response to 'foundational gaps', but also as a response to increasing complexity of the professional field. The most significant structural reform is the weaving of 'application' opportunities (drawing on the appropriate disciplinary content) through the curricula. In other words, there is a defined pattern of theory/practice sequencing which sees more time for both conceptual development and contextual application, with the latter becoming increasingly complex and situated in relation to the profession itself. The exemplars demonstrate significant structural reform in addressing the need for the application of knowledge in complex, professional contexts through a 'woven' as opposed to 'add-on' approach to the required knowledge practice development.

\section{Discussion and Conclusion}

In this paper we seek to answer the question 'how are the proposed models of curriculum reform different to the existing Bachelors/Diploma and existing extended curriculum models'? The principle difference is more time, but more time for what? Given that more time is a necessary but not sufficient condition, the fundamental difference between the models of curriculum reform represented by the CHE proposal and the status quo is that the new structure is designed to enable epistemic access and development. In order to elaborate on what this might mean, we offered some tools for conceptualising different types of knowledge, knowledge structures, curriculum 'logics' and qualification purposes. Drawing on the CHE exemplars, the implications of these differences for different models of curriculum were then discussed.

In contrast to the existing 3-year Bachelor's but consistent with the existing extended degrees/diplomas, the curriculum reform models unequivocally acknowledge and address the structural articulation gap between secondary school provision and university preparedness. The models are premised on a fundamentally different set of assumptions about the necessary entry point conceptual foundations. It assumes that these conceptual foundations are required for the majority, not the current minority who benefit from extended curriculum programmes. In contrast to existing extended curriculum provision, the main difference is that the proposed curriculum models assume that epistemic access and development is not something which can be achieved in a year - the epistemic journey is a long one. While the extended programmes have made an important contribution, they have not been as successful as they 
need to be. In some cases, particularly in science and engineering, the cohort completion rates are dismal. Further analysis in Phase 2 of the research will attempt to explore this in more detail.

Higher Education in South Africa finds itself at a critical crossroad. The 1997 White Paper (DoE, 1997) commits us simultaneously to the imperatives of redressing the inequalities of the past and addressing the needs for growth in an increasingly competitive global future. In South Africa the imperatives of growth cannot be achieved without redress. The CHE's proposal for curriculum reform offers a means for navigating this tension by offering curriculum models which are intended to ensure more appropriate admissions and placement and ultimately improved completion rates. The findings of the second phase of this project reveal that those extended curriculum programmes which are modelled on these principles have significantly higher completion rates than others and in some cases outperform their mainstream variants (Shay, Wolff and Clarence-Fincham, 2016).

In the introduction to this paper the urgency of systemic reform was noted given the on-going student protests that rocked the higher education sector in South Africa. What is the contribution of these proposed curriculum reform measures in the current political landscape?

Firstly, this reform is unambiguous in its commitment to addressing the continuing inequalities of educational provision and the consequential uneven playing field that a significant proportion of university students experience. This increasingly inequitable access to and success through higher education is not a unique South African post-apartheid phenomenon. It is a feature of the global landscape and gaining attention as a global reform imperative $^{5}$. It is likely that local research and development will increasingly attract global attention given the long-track record of work in this area. Secondly, this curriculum reform speaks directly to the perceptions of stigmatisation expressed by students over the years (but forcefully in 2015) in their experience of existing foundational or extended curriculum provision. These experiences may be more acute for black students in historically white universities where the educational, financial and cultural capital disparities may be particularly marked. This reform addresses these stigmatising structural and cultural conditions by problematising the status quo which is contributing to the failure of the higher education system; it 'normalises' the need for 'more time' for a more enabling curriculum. Thirdly, the curriculum reform puts access to knowledge, or epistemic access, as its key rationale.

The student protests have called for a 'decolonised curriculum' where curriculum knowledge has come under an intense spotlight: what knowledge, whose knowledge, whose ways of knowing? This is not a question of who has access to the knowledge 'goods' but challenging what and whose 'goods'. It is too early to anticipate what curriculum reform agenda will emerge from this. 'Decolonising' economics will pose different challenges to 'decolonising' chemistry. There is no doubt, however, that these are critical debates. Curriculum reform which prioritises 'epistemic access', that is, giving students access to 'powerful knowledge' (Young, 2008) may well-serve this critical agenda, it may indeed be

\footnotetext{
${ }^{5}$ As well-demonstrated at a post-conference session of Going Global Conference 2016 entitled Inequitable Access to Higher Education: Making the Global Case. https://www.britishcouncil.org/goingglobal/programme/post-conference-sessions/equitable-access-higher-education
} 
essential. After all, it will take adeptness in disciplinary knowledge and ways of knowing in order to disrupt and transform them.

In the preface to the CHE proposal, Ndebele writes: "This publication is one of an increasing number of signals that South African democracy is entering the second stage of its historic new life". He notes that a marked feature of these 'signals' is the diligent critique of a "future more evoked than realised in self-conscious effort: a future that keeps receding because it seems to disappear in a murky and unfocussed present severely lacking in human capacity" (CHE, 2013: 8). The CHE's curriculum models provide the academic community in South Africa the opportunity to consider a systemic response to curriculum reform which enables epistemic access and ultimately contributes to greater equity of access and success.

\section{Acknowledgement}

This research was made possible through funding from the Department of Higher Education and Training's collaborative Teaching Development Grant.

Suellen Shay is Associate Professor and Dean in the Centre for Higher Education Development (CHED) at the University of Cape Town. Her career has spanned a range of language, curriculum, staff and institutional development work. Her research attempts to bring the theoretical frameworks of sociology of education to an understanding of higher education as social practice, specifically focusing on assessment, knowledge and curriculum.

Karin Wolff is a post-doctoral research fellow with the SARChI Work Integrated Learning initiative, hosted by the Cape Peninsula University of Technology. In addition to staff development work in curriculum, teaching and learning, her research looks at multidisciplinary engineering knowledge practices across industrial sectors.

Jennifer Clarence-Fincham is a senior teaching and learning specialist currently working at Nelson Mandela Metropolitan University. Her special interests include Critical Discourse Analysis, curriculum development and the Scholarship of Teaching and Learning from a social justice perspective.

\section{References}

Badat, S. 2015. Social Justice in Higher Education: Universities, State, and Philanthropy. The advancement and financing of the social justice mission of Higher Education institutions: A symposium, 29 March. Cape Town.

Bernstein, B. 1975. Class, codes \& control (Vol. III). London: Routledge.

Bernstein, B. 2000. Pedagogy, symbolic control and identity: Theory, research, critique. (Revised edition). London: Rowman \& Littlefield.

Case, J. 2011. Knowledge matters: interrogating the curriculum debate in engineering using the sociology of knowledge. Journal of Education (51): 1-20.

CHE. 2013. A proposal for undergraduate curriculum reform in South Africa. Pretoria: Council on Higher Education. 
De Vos, P. 2014. Can the constitution respond to the challenge of addressing South Africa's inequality? The South African Civil Society Information Service, 29 August. Online at: http://sacsis.org.za/site/article/2117 (accessed 2 January 2016).

DOE. 1997. Education White Paper 3: A Programme for the Transformation of Higher Education. Government Gazette, Vol. 386, No. 18207, Notice 1196 of 1997, July.

Maton, K. 2014. Knowledge and Knowers: Towards a realist sociology of education. London and New York: Routledge.

Morrow, W. 2009. Bounds of democracy: epistemological access in higher education. Cape Town: HSRC Press.

Muller, J. 2009. Forms of knowledge and curriculum coherence. Journal of Education and Work, 22(3): 205-226.

Muller, J. 2014. Every picture tells a story: Epistemological access and knowledge. Education as Change, 18(2): 255-269.

Muller, J. 2015. The future of knowledge and skills in science and technology higher education. Higher Education, 70(3): 409-416.

Shay, S., Wolff, K., \& Clarence-Fincham, J. 2016. New Generation Extended Curriculum Programmes: Report to the DHET. Cape Town: University of Cape Town.

Winch, C. 2013. Curriculum design and epistemic ascent. Journal of Philosophy of Education, 47(1): 128-146.

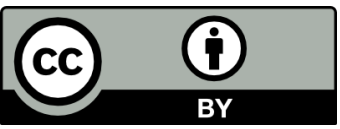

This publication is covered by a Creative Commons Attribution 4.0 International license. For further information please see: http://creativecommons.org/licenses/by/4.0/. 